\title{
O Processo Decisório em Propriedades Rurais: análise do uso das ferramentas de gestão pelos produtores de leite do Triângulo Mineiro
}

Paulo Henrique Fonseca de Melo Mestrado em Ciências Contábeis pela Universidade Federal de Minas Gerais - UFMG Av. Pres. Antônio Carlos, 6627. Pampulha. Belo Horizonte/MG. CEP: 31270-901

E-mail:phfons@gmail.com

Jacqueline Veneroso Alves da Cunha Doutorado em Ciências Contábeis pela Universidade de São Paulo - USP Professora da Universidade Federal de Minas Gerais - UFMG Av. Pres. Antônio Carlos, 6627. Pampulha. Belo Horizonte/MG. CEP: 31270-901 E-mail: jvac@face.ufmg.br

Norton Cruz Freitas Bahia Especialização em andamento em Perícia Judicial e Práticas Atuariais com Docência pelo Instituto de Tecnologia e Complementação Profissional Ltda - ITCP CRS Sul. Bloco C. Lote 03. Loja 60/64. Subsolo. Brasília/DF. CEP: 70331-535

E-mail: norton.bahia@gmail.com

\section{RESUMO}

A contabilidade rural tem grande importância para o processo decisório no agronegócio, e se caracteriza como um dos principais sistemas de controle e informação dos empreendimentos rurais. Esta pesquisa tem por objetivo verificar quais ferramentas de gestão que pequenos e médios produtores de leite vêm utilizando para subsidiar suas decisões. Trata-se de estudo descritivo, com realização de entrevistas semiestruturadas com produtores de leite associados da Cooperativa Mista Agropecuária de Patos de Minas Ltda. (Coopatos), e, ainda, utilização de técnicas quantitativas para análise dos resultados. Constatou-se, entre pequenos produtores, desconhecimento generalizado no tocante a ferramentas contábeis, sendo que a maioria deles utiliza contabilidade para fins meramente fiscais. Verificou-se interesse por parte dos produtores em contar com ferramentas gerenciais, sendo a desfavorável relação custo-benefício apontada como responsável pela sua não adoção. Encontraram-se evidências do uso de instrumentos informais, como anotações manuais, planilhas eletrônicas e experiência como principais e, às vezes, únicos instrumentos. Outra constatação diz respeito à preocupação com a expertise dos profissionais contábeis, o que se caracteriza como um dos grandes desafios do processo de convergência contábil internacional. Observou-se que na medida em que aumenta a demanda por informações, a contabilidade ganha mais espaço, e maiores empreendimentos passam a utilizar ferramentas contábeis. Observa-se que o agronegócio, contando com assessoria técnica e contábil, além de apoio das classes representativas e incentivos 
O Processo Decisório em Propriedades Rurais: análise do uso das ferramentas de gestão pelos produtores de leite do Triângulo Mineiro

Paulo Henrique Fonseca de Melo, Jacqueline Veneroso Alves da Cunha, Norton Cruz Freitas Bahia

governamentais, destaca-se na economia. Para tanto, a distância entre produtor e contador deve ser reduzida no cenário de crescimento e fortalecimento do agronegócio.

Palavras-chave: Contabilidade rural. Ferramentas gerenciais. Produtor rural.

\section{The Decision Making Process in Rural Properties: analysis of the use of management tools by milk producers of the Triângulo Mineiro}

\section{ABSTRACT}

The rural accounting is very important for decision-making in agribusiness, and is characterized as one of the control and information of rural enterprise systems. This research aims to determine which small management tools and medium dairy farmers have been using to support their decisions. This is a descriptive study, with carrying out semi-structured interviews with milk producers associated with the Agricultural Mixed Cooperative of Patos de Minas Ltda. (Coopatos), and also use of quantitative techniques to analyze the results. It was found among small producers, widespread ignorance regarding accounting tools, and most of them use accounting for tax purposes only. There was interest from producers to rely on management tools, and the unfavorable cost-benefit identified as responsible for not adopting. They met evidence of the use of informal means, such as manual notes, spreadsheets and experience as the main and sometimes only instruments. Another finding relates to concerns about the expertise of financial professionals, which is characterized as one of the great challenges of the international accounting convergence process. It was observed that the extent that increases the demand for information, accounting get more space and larger enterprises begin to use financial tools. It is observed that the agribusiness, with technical and accounting advice, and support of representative classes and government incentives, there is the economy. Therefore, the distance between producer and counter should be reduced in the growth scenario and strengthening agribusiness.

Keywords: Rural Accounting. Management tools. Rural producer.

\section{INTRODUÇÃO}

As propriedades rurais convivem em um ambiente de frequentes mudanças, inseridas em um setor que trabalha com grandes adversidades, como as irregularidades climáticas e pluviométricas, as oscilações nos preços de venda de seus produtos e um mercado permanentemente influenciado por grandes oligopólios que se formam no meio rural (DALMOLIN; SILVÉRIO, 2011). 
O Processo Decisório em Propriedades Rurais: análise do uso das ferramentas de gestão pelos produtores de leite do Triângulo Mineiro

Paulo Henrique Fonseca de Melo, Jacqueline Veneroso Alves da Cunha, Norton Cruz Freitas Bahia

Adaptar-se a essa realidade é crucial para a continuidade dessas entidades. Por essa razão, é frequente a busca pelo desenvolvimento de ferramentas e controles que possibilitem aos gestores as melhores decisões, suportados por informações disponibilizadas, por exemplo, pela contabilidade e, mais especificamente, pela contabilidade rural, preparando-os e atualizando-os para eventuais mudanças, e assim contribuindo para uma adequada gestão dos recursos. Cabe salientar que aspectos relacionados a melhoramento genético, qualidade do leite, do solo e dos insumos são fatores que também devem ser avaliados com o auxílio de ferramentas contábeis, que permitirão uma melhor análise - por meio de índices, relatórios, orçamentos -, possibilitando, consequentemente, uma gestão eficaz dos recursos (ATSBEHA et al., 2012). A contabilidade rural, embora pouco explorada, quando apoiada por relatórios gerenciais, configura-se como uma importante ferramenta.

A área rural é um ambiente que oscila significativamente e cresce dentro do país, sendo seus produtos responsáveis por uma grande movimentação financeira, resultante de grandes exportações de leite, soja, açúcar, milho, entre outros. Por trabalhar com diversas variáveis, do preparo da terra e plantio até a venda do produto, e diante de adversidades, principalmente as pequenas propriedades rurais precisam cada dia mais estar atentas no que diz respeito às mudanças, para obterem as melhores ferramentas para subsidiar suas decisões. É nessa esfera de desafio que se encaixa a contabilidade rural, provida de meios para gerar relatórios e informações úteis e relevantes (DALMOLIN; SILVÉRIO, 2011).

Os estabelecimentos rurais brasileiros caracterizados como minifúndios ainda tentam sobreviver, mas tem sofrido com a rápida transformação tecnológica e industrialização por que passa o setor. Cabe destacar que projetos e gerenciamento em entidades rurais envolvem diversos fatores operacionais, econômicos, políticos e sociais, inter-relacionados, devido à complexidade da temática (KHENE et al., 2011).

Nesse sentido, Stroeher e Freitas (2008) concluíram que se atribui importância significativa às informações contábeis em pequenas empresas rurais, quando os proprietários delas dispõem e as utilizam no processo decisório e gestão de suas 
O Processo Decisório em Propriedades Rurais: análise do uso das ferramentas de gestão pelos produtores de leite do Triângulo Mineiro

Paulo Henrique Fonseca de Melo, Jacqueline Veneroso Alves da Cunha, Norton Cruz Freitas Bahia

propriedades (mesmo que nem todos as utilizem). Isso porque essas informações são úteis para analisar o nível de faturamento, os custos e despesas das lavouras e rebanhos, o percentual de lucratividade, a formação de preço de venda, dentre outros. Além do mais, os resultados apresentados estabelecem a necessidade da conscientização dos proprietários sobre a potencialidade de profissionais contábeis na gestão de pequenas empresas.

Sell (2004) sugere a elaboração de uma sistemática que consiga inserir a contabilidade de forma gradual nas pequenas e médias empresas, em especial suas ferramentas gerenciais, com o objetivo de gerar conhecimentos para os gestores, de modo a facilitar o processo decisório. Em torno disso, Hofer et al., (2006) evidenciam o controle dos custos de produção, o planejamento com base na lucratividade e a maior organização nas atividades como ferramentas que geram subsídios para os administradores rurais no momento de tomar decisões.

Diante disso, este estudo procura responder à seguinte questão de pesquisa: Quais ferramentas de gestão os pequenos e médios produtores de leite vêm utilizando para subsidiar suas decisões? Assim, o objetivo desta pesquisa consiste em identificar as ferramentas de gestão que os pequenos e médios produtores de leite do triângulo mineiro vêm utilizando para subsidiar suas decisões. Adicionalmente, pretende-se identificar em que nível essas ferramentas vêm sendo empregadas. Para responder a tal indagação, o presente estudo se baseou na Teoria de Crescimento da Firma, que procura compreender o processo de crescimento das empresas e as limitações internas e externas à sua expansão. Portanto, estabelece os limites de crescimento a partir da capacidade do empresário de identificar oportunidades produtivas que possam ser exploradas (PENROSE, 2006).

A realização deste estudo se justifica pelo fato das atividades agrícolas se caracterizarem como atividades complexas, e que por isso devem ser controladas, para viabilizar análises periódicas de desempenho, proporcionando decisões de mais qualidade, já que a contabilidade pode fornecer importantes ferramentas para a gestão. A inexistência de fontes de informações confiáveis frequentemente leva os produtores a 
O Processo Decisório em Propriedades Rurais: análise do uso das ferramentas de gestão pelos produtores de leite do Triângulo Mineiro

Paulo Henrique Fonseca de Melo, Jacqueline Veneroso Alves da Cunha, Norton Cruz Freitas Bahia

tomar decisões condicionadas à sua experiência, à tradição, ao potencial da região, à falta de outras opções e à disponibilidade de recursos financeiros e de mão de obra. Quando a rentabilidade é baixa, geralmente o produtor percebe; mas enfrenta grande dificuldade para quantificar e identificar as restrições do processo produtivo.

\section{REFERENCIAL TEÓRICO}

\subsection{Teoria de Crescimento da Firma}

A abordagem deste estudo considera a Teoria de Crescimento da Firma, que tem por objetivo entender as oportunidades máximas internas e externas para a ampliação da empresa e compreender o seu processo de crescimento; ou seja, identifica as oportunidades de crescimento da firma com base na capacidade do gestor de evidenciar oportunidades produtivas que possam ser aproveitadas no processo administrativo-gerencial (ALMEIDA et al., 2012).

Nesse sentido, Penrose (2006) aborda que os limites do tamanho da firma se relacionam com as economias de tamanho e crescimento, nas quais a importância das economias de escala na produção, na comercialização, na obtenção de financiamento e na administração dos recursos está no sentido de economias de tamanho, e também na capacidade de reorganização da estrutura administrativa, no sentido de garantir a manutenção ou a ampliação dos rendimentos, comparativamente ao crescimento da firma.

Assim, os limites de crescimento da firma estariam condicionados à competência empresarial para conseguir imaginar e analisar alternativas de negócios, por meio da diversificação da produção e da expansão de negócios, ou ainda da disponibilização de investimentos para novos produtos, recombinando os recursos produtivos disponíveis (SANTOS et al., 2007).

Diante disso, o conhecimento técnico, econômico e financeiro é imprescindível para determinar o sucesso do gestor na agropecuária. Portanto, na aplicação da Teoria de Crescimento da Firma, o conhecimento técnico é fundamental na definição dos 
O Processo Decisório em Propriedades Rurais: análise do uso das ferramentas de gestão pelos produtores de leite do Triângulo Mineiro

Paulo Henrique Fonseca de Melo, Jacqueline Veneroso Alves da Cunha, Norton Cruz Freitas Bahia

recursos disponíveis para o empresário diversificar a produção. No aspecto econômico, as operações de custos de produção relacionadas a seus resultados, através dos quais se obtém o lucro, e, na questão financeira, as medidas relacionadas à captação e aplicação de recursos com o objetivo de manter o equilíbrio financeiro do negócio, contribuem diretamente e de forma significativa para análise de fatores como diversificação da produção em busca de melhor performance e crescimento da firma (HOFER et al., 2006).

Considerando-se que a expansão das atividades é uma pauta permanente no processo decisório das empresas, independentemente das condições externas, sempre há oportunidades de expansão, sendo imprescindível, nesse sentido, a obtenção de ferramentas de controle que possibilitem aos gestores identificar e analisar, além de seus pontos fortes e fracos, as ameaças e oportunidades no ambiente em que estão inseridos, em prol da obtenção de vantagem competitiva, melhores resultados e crescimento (AVELAR et al., 2011).

\subsection{A gestão nas pequenas e médias empresas}

No atual contexto empresarial, a informação é um recurso imprescindível, podendo representar uma vantagem competitiva para determinadas organizações. Muitos autores, dentre eles Goldratt (1991), McGee e Prusak (1994), Davenport (2000) e Beuren (2000), abordam a importância da informação para as entidades inseridas em um ambiente globalizado e a cada dia mais competitivo. Nesse sentido, vale ressaltar a importância atribuída à contabilidade, já que ela é responsável por suprir seus usuários, sejam eles internos ou externos, de informações relevantes acerca de suas atividades (STROEHER; FREITAS, 2008).

Portanto, implementar melhorias no negócio é fundamental para a sobrevivência no mercado. As demandas mudam frequentemente, e cabe ao empresário adequar a gestão, seus produtos e serviços às exigências dos clientes. Orientações e ferramentas sobre como inovar no negócio, aperfeiçoar a gestão administrativa e financeira, expandir o empreendimento e tornar a empresa mais competitiva são fundamentais. 
O Processo Decisório em Propriedades Rurais: análise do uso das ferramentas de gestão pelos produtores de leite do Triângulo Mineiro

Paulo Henrique Fonseca de Melo, Jacqueline Veneroso Alves da Cunha, Norton Cruz Freitas Bahia

Entretanto, para obter sucesso em seu negócio, o empreendedor deve ter espírito criativo e pesquisador. É preciso buscar novos caminhos e soluções para atender às necessidades da clientela e do mercado (SEBRAE, 2013).

Stroeher e Freitas (2008) enfatizam que frequentemente os empresários vinculam a contabilidade ao pagamento dos tributos e ao excesso de fiscalização por parte dos entes federativos, haja vista que grande parte dos trabalhos realizados pelos contadores se relaciona à área fiscal. Nesse sentido, os empresários argumentam que devido às políticas fiscais, ao alto custo da burocracia, da carga tributária, além das inúmeras obrigações acessórias, torna-se oneroso e, na maior parte das vezes, inviável, para as pequenas empresas a contratação de especialista em contabilidade na área gerencial ou financeira (SELL, 2004).

A quantidade de dados e informações a que as empresas ficam expostas diariamente, no curso de suas atividades, demanda um gerenciamento eficaz, sendo esse aspecto parte integrante do processo decisório dentro das organizações. Se administrar é decidir, a continuidade de qualquer negócio depende das decisões tomadas pelos gestores (STROEHER; FREITAS, 2008). Além disso, empreender é identificar oportunidades e desenvolver meios de aproveitá-las, assumindo riscos e desafios, e, para isso, o uso de ferramentas como a contabilidade se torna fator de extrema relevância (SEBRAE, 2013).

Contudo, devido à sua relevância para a gestão das pequenas empresas, a contabilidade deve ser elaborada de forma simples, transparente, objetiva e confiável, respeitando as especificidades do contexto, para possibilitar a compreensão por parte dos pequenos empresários. Corroborando essa ideia, os indicadores de ponto de equilíbrio, endividamento, faturamento, custos, despesas, preço de venda e margem de lucro são as principais necessidades na gestão dos negócios das pequenas empresas, por se caracterizarem como informações mais simples e de cunho fundamental para a sua continuidade (STROEHER; FREITAS, 2008).

A maioria das decisões que dão suporte às boas práticas de produção de leite tem implicações financeiras para o empreendimento rural. $O$ uso de sistemas de 
O Processo Decisório em Propriedades Rurais: análise do uso das ferramentas de gestão pelos produtores de leite do Triângulo Mineiro

Paulo Henrique Fonseca de Melo, Jacqueline Veneroso Alves da Cunha, Norton Cruz Freitas Bahia

anotação e registros que forneçam informações atualizadas sobre a situação financeira da propriedade é crucial. $O$ acesso e análise dessas informações facilitam a tomada de decisões acertadas. Implementar boas práticas de produção de leite facilita a adaptação às mudanças, já que o ambiente físico e o mercado dos produtores rurais sofrem mutações frequentes. Nesse âmbito, os produtores de leite são desafiados a implementar novas tecnologias e práticas que sejam consistentes para o alcance de seus objetivos (IRWIN et al., 2010).

Um exemplo claro da importância da gestão nas pequenas e médias empresas, mais especificamente nas pequenas e médias propriedades rurais, é que o planejamento prévio de receitas e despesas deve ser usado para gerenciar riscos financeiros. Esse planejamento pode ajudar a identificar e gerenciar futuros problemas de fluxo de caixa, bem como minimizar os custos de financiamento.

King et al., (2010) definem o termo agronegócio como a soma total de todas as operações envolvidas na fabricação e distribuição de insumos agrícolas, as operações de produção na fazenda, o armazenamento, processamento e distribuição de commodities agrícolas e, inclusive, itens gerados a partir deles. Nesse sentido, independentemente do porte da empresa, a contabilidade como ferramenta aplicada ao agronegócio contribui com toda a cadeia de suprimentos para melhorar a eficácia das decisões nos fluxos de produção, informações e recursos financeiros.

Ulrich (2009) ressalta que o gestor do agronegócio deve estar sempre em afinidade estreita com a contabilidade, pois esta serve não apenas para the informar sobre créditos ou débitos, serve para lhe mostrar quais os possíveis caminhos a serem trilhados, evitando riscos desnecessários, visando a lucratividade, crescimento e eficácia na gestão.

\subsection{A contabilidade como ferramenta de gestão}

Há nas empresas uma multiplicidade de fontes de informações e ferramentas de gestão. Entre as várias fontes, destaca-se a contabilidade, responsável por todo o processo de mensuração, registro e comunicação dos fatos que envolvem a atividade 
O Processo Decisório em Propriedades Rurais: análise do uso das ferramentas de gestão pelos produtores de leite do Triângulo Mineiro

Paulo Henrique Fonseca de Melo, Jacqueline Veneroso Alves da Cunha, Norton Cruz Freitas Bahia

empresarial. Nesse sentido, a contabilidade tem como principal função suprir de informações relevantes os gestores, a fim de capacitá-los a alcançar os objetivos da organização, via gestão eficiente de seus recursos. A contabilidade possibilita à empresa coletar, processar e relatar informações para uma variedade de decisões operacionais e administrativas (STROEHER; FREITAS, 2008).

O principal objetivo da contabilidade rural compreende o controle, a apuração do resultado e a prestação de informações sobre o patrimônio das entidades rurais. É fator de grande relevância, já que a atividade rural também necessita de uma gestão efetiva e aplicada, o que permitirá uma melhor visão do retorno financeiro da atividade, bem como observar se os objetivos vêm sendo atingidos. Para o agronegócio, deve-se considerar uma complexa rede de troca de mercadorias, serviços, dinheiro e informações que ocorrem entre os diversos fatores de uma cadeia produtiva, desde os fornecedores de insumos e outros bens e serviços antes da porteira, passando pela produção agropecuária em si, e os fatores integrantes da porteira, como agroindústrias e distribuidores, até chegar ao consumidor final. Dessa forma, por se tratar de uma atividade de grande relevância para a economia, é fundamental a utilização de ferramentas advindas da contabilidade, em prol da eficiência no que tange à gestão de recursos, sejam eles materiais, tecnológicos ou humanos (GOMES, 2006).

Conhecer a situação econômico-financeira da empresa é condição essencial para o gestor que pretende ver seus negócios evoluírem. Isso porque as informações contábeis são pré-requisitos estratégicos para subsidiar decisões gerenciais. Sempre que adquire matéria-prima, contrata um empregado ou paga um fornecedor, a empresa está efetuando gastos. Por meio do acompanhamento contábil, a empresa gera informações importantes sobre o negócio e a respeito de seus gastos, custos e despesas, a partir de importantes relatórios, capazes de fornecer relevantes informações (SEBRAE, 2013).

Hofer et al., (2010) destacam que cem por cento dos produtores rurais, sejam pequenos ou médios, buscam algum tipo de financiamento entre as diversas linhas de crédito disponíveis, com o objetivo de fazer novos investimentos ou para aplicar em 
O Processo Decisório em Propriedades Rurais: análise do uso das ferramentas de gestão pelos produtores de leite do Triângulo Mineiro

Paulo Henrique Fonseca de Melo, Jacqueline Veneroso Alves da Cunha, Norton Cruz Freitas Bahia

custeio. Diante desse cenário, a contabilidade utilizada no processo de gestão das atividades agropecuárias contribui orientando as operações no sentido de estabelecer com antecedência as ações que serão executadas e estimando os recursos a serem empregados de forma eficiente, tendo como objetivo facilitar as decisões sobre as melhores oportunidades de negócio. King et al. (2010) salientam que o agricultor tem a necessidade de aprender a usar o crédito de forma inteligente, para não vir a ser controlado por ele.

Destarte, a entidade é o bem maior de todo empreendedor, já que é por meio dela que serão desenvolvidos todos os atos administrativos e comerciais com finalidade de lucro e/ou de bem comum (GOMES, 2006). A contabilidade é uma ciência que auxilia o processo decisório, já que proporciona aos sócios, aos administradores, ao governo e à sociedade uma visão mais ampla e definida do patrimônio da entidade, apresentando seus pontos fortes e fracos sempre que necessário. Nesse sentido, a entidade poderá ainda, além de identificar seus pontos fortes e fracos, analisar e elaborar estratégias levando em conta as ameaças e oportunidades do mercado (Sell, 2004).

Entretanto, Kruger et al. (2014) identificaram a carência na utilização da contabilidade como instrumento de apoio e controle para a gestão das propriedades rurais. Elevados níveis de desconhecimento e falta de controle de procedimentos de gestão proporcionados pela contabilidade foram verificados neste estudo. Além disso, percebeu-se que muitos produtores não separam os gastos particulares dos gastos com a atividade rural, inviabilizando maiores análises em consequência da ausência da contabilidade no meio rural. Corroborando, os resultados de Bastos (2011) ressaltam a fragilidade da contabilidade rural como instrumento de gestão. Os resultados evidenciam que, em geral, a contabilidade rural é uma lacuna na formação dos profissionais contábeis pesquisados no estado do Ceará e que seus conhecimentos sobre o tema são bastante limitados. Sendo assim, percebe-se que são enormes as limitações da contabilidade rural como instrumento de apoio e gestão das propriedades rurais no Brasil sendo, imprescindível, a difusão de seus conceitos e procedimentos, 
O Processo Decisório em Propriedades Rurais: análise do uso das ferramentas de gestão pelos produtores de leite do Triângulo Mineiro

Paulo Henrique Fonseca de Melo, Jacqueline Veneroso Alves da Cunha, Norton Cruz Freitas Bahia

tanto a usuários quanto aos produtores da informação contábil, para que esta possa refletir com essência as transações ocorridas no meio rural.

\subsection{Gestão profissional e informalidade na gestão}

A informalidade na gestão das pequenas e médias empresas do agronegócio está, na maioria das vezes, relacionada com a redução da carga tributária, as obrigações acessórias e a fiscalização por parte de entidades governamentais. Os ganhos proporcionados pela informalidade são superiores àqueles proporcionados pela isenção de impostos, por exemplo. Nesse sentido, cabe dizer que a informalidade não se caracteriza como um fenômeno de causa única, mas é o resultado da conjunção de diversos elementos do ambiente institucional e competitivo, que se somam ao garantir mais vantagens ao produtor informal (AZEVEDO; BANKUTI, 2001; BANKUTI; SOUZA FILHO, 2006).

Sendo assim, em sentido inverso, os produtores, independentemente do porte, podem se apoiar em ferramentas contábil-financeiras que lhes proporcionarão uma gestão adequada dos recursos, reduzindo a carga tributária, por exemplo, a partir de um planejamento tributário, e não por meio da informalidade. Enfim, percebe-se a importância da utilização de ferramentas, sejam elas econômicas, contábeis ou financeiras, por parte de qualquer gestor, independentemente do porte da empresa ou do setor em que está inserida (AZEVEDO; BANKUTI, 2001).

A inovação e a criação de novas empresas apresentam certa sinergia quando se trata de pequenas e médias empresas. Por um lado, a inovação é um tema essencial e clássico em empreendedorismo, e também central em estratégia das pequenas e médias empresas (PMEs), pois constitui o meio pelo qual essas organizações obtêm diferencial competitivo e buscam melhores perspectivas de sobrevivência e desenvolvimento. Por outro lado, além de ser muito recorrente como foco de estudo em empreendedorismo, a criação da empresa constitui a primeira grande decisão em termos estratégicos da direção de uma PME, cuja realização estabelece as bases de sua interação com os concorrentes, com o ambiente externo em geral e com os 
O Processo Decisório em Propriedades Rurais: análise do uso das ferramentas de gestão pelos produtores de leite do Triângulo Mineiro

Paulo Henrique Fonseca de Melo, Jacqueline Veneroso Alves da Cunha, Norton Cruz Freitas Bahia

diversos atores e recursos internos e externos que a influenciam. Em suma, o ensino de gestão de PME e, mais especificamente, de estratégia de PME complementa a formação em empreendedorismo, e vice-versa (VALENTIM, 2003).

\section{METODOLOGIA}

Esta pesquisa pode ser classificada como de caráter descritivo, quanto aos objetivos, já que descreve as ferramentas gerenciais e verifica em que nível elas são utilizadas pelos produtores rurais. Apoia-se na estratégia de pesquisa denominada levantamento, ou survey, por meio de entrevistas semiestruturadas como técnica de coleta de dados, com questões abertas e fechadas. As entrevistas permitem mais interação e conhecimento da realidade dos sujeitos da pesquisa. Foram utilizadas, ainda, técnicas quantitativas para análise dos resultados obtidos na pesquisa. Recursos bibliográficos também foram utilizados na busca de suporte teórico para realização da investigação.

Importa ressaltar ainda que o instrumento de coleta de dados foi adaptado da pesquisa de Hofer et al., (2010), que investigaram o uso de ferramentas contábeis nas empresas rurais. Foram elaborados 20 quesitos objetivando dar suporte às entrevistas semiestruturadas, compreendendo aspectos relacionados às ferramentas de gestão que os pequenos e médios produtores rurais vêm utilizando para melhorar a eficácia das decisões, conforme indicado pela literatura. São igualmente explorados fatores relacionados ao conhecimento dos gestores rurais sobre contabilidade rural e seus benefícios, além de aspectos relacionados à atividade rural e atividades de planejamento, controle e execução. Além disso, procurou-se elucidar se variáveis como tamanho e endividamento são preponderantes para a inserção da contabilidade no agronegócio, e em que nível as ferramentas contábil-financeiras vêm sendo utilizadas por pequenos e médios produtores rurais.

Para enquadramento das empresas rurais como pequenas e médias, foi considerada a produção de leite de cada propriedade. Assim, um faturamento anual de 
O Processo Decisório em Propriedades Rurais: análise do uso das ferramentas de gestão pelos produtores de leite do Triângulo Mineiro

Paulo Henrique Fonseca de Melo, Jacqueline Veneroso Alves da Cunha, Norton Cruz Freitas Bahia

até $R \$ 150.000,00$ foi estabelecido para as pequenas empresas rurais, e um valor maior, mas limitado a $R \$ 400.000,00$, foi considerado como de médias empresas rurais, haja vista que o faturamento corresponde ao volume médio da produção anual de leite por empresa. Ou seja, foi estabelecida uma produção diária máxima de 400 litros para pequenos produtores, e de 1.200 litros para médios produtores rurais, como aponta a Cooperativa Mista Agropecuária de Patos de Minas Ltda. (Coopatos), em Minas Gerais.

A amostra foi definida por relevância e acessibilidade, reunindo gestores das propriedades rurais associadas à Coopatos. A escolha da amostra se deu pelo fato de que, analisando os resultados dos 100 maiores produtores de leite no Brasil em 2013, pôde-se observar que Minas Gerais é o principal estado produtor de leite, com $41 \%$ dos produtores e líder no número de fazendas; e Patos de Minas é a segunda cidade com maior produção nacional de leite (IBGE - Instituto Brasileiro de Geografia e Estatística, 2013). Além disso, dois dos maiores produtores rurais do Brasil comercializam a produção de leite pela Coopatos, que conta hoje com 1.640 cooperados no total, sendo 416 produtores rurais fornecedores de leite, ratificando, assim, a importância do estudo e das ferramentas utilizadas pelos cooperados na gestão de suas propriedades (MILKPOINT, 2013).

\section{ANÁLISE DE RESULTADOS}

Foram entrevistados 42 produtores rurais associados da Coopatos, no período de outubro a dezembro de 2013. A partir dos 20 quesitos elaborados para dar suporte à pesquisa foram produzidas descrições quantitativas da amostra pesquisada. A partir destas descrições quantitativas e dos quesitos suporte foram transcritos e catalogados os principais resultados que se relacionam com o nível de utilização das ferramentas contábeis por parte dos produtores rurais.

A maioria dos entrevistados se caracteriza como pequenos produtores rurais (64,3\%), com faturamento bruto anual inferior a 150 mil reais, e possui ensino médio 
O Processo Decisório em Propriedades Rurais: análise do uso das ferramentas de gestão pelos produtores de leite do Triângulo Mineiro

Paulo Henrique Fonseca de Melo, Jacqueline Veneroso Alves da Cunha, Norton Cruz Freitas Bahia

completo $(69 \%)$, sendo que grande parte deles utiliza a própria experiência como principal e, às vezes, único instrumento para subsidiar suas decisões.

Nesse contexto, à medida que cresce o empreendimento rural, aumenta a demanda por instrumentos provenientes da contabilidade, mais especificamente da contabilidade rural, sendo utilizados pelos produtores rurais em suas atividades. Por meio da coleta de dados, foi possível verificar que $64,3 \%$ dos entrevistados se situam na faixa até 150 mil reais de faturamento anual, recorrendo, na maioria das vezes, apenas ao auxílio da planilha eletrônica Excel e de outros mecanismos informais, como anotações feitas à mão, para controle e consequente tomada de decisões. Entretanto, dos $15(35,7 \%)$ entrevistados com faturamento superior a 150 mil reais, sete $(46,7 \%)$ afirmam não possuir assessoria contábil, usando a contabilidade apenas para cumprir as demandas obrigatórias fiscais e trabalhistas, assim como ocorre com nove $(33,3 \%)$ dos pequenos produtores rurais. $O$ Gráfico 1 apresenta a relação entre utilização de ferramentas gerenciais e nível de faturamento das entidades. É possível notar que, como preconiza a Teoria de Crescimento da Firma, existe uma relação entre o tamanho (considerando o faturamento) das propriedades rurais e a utilização das ferramentas gerenciais.

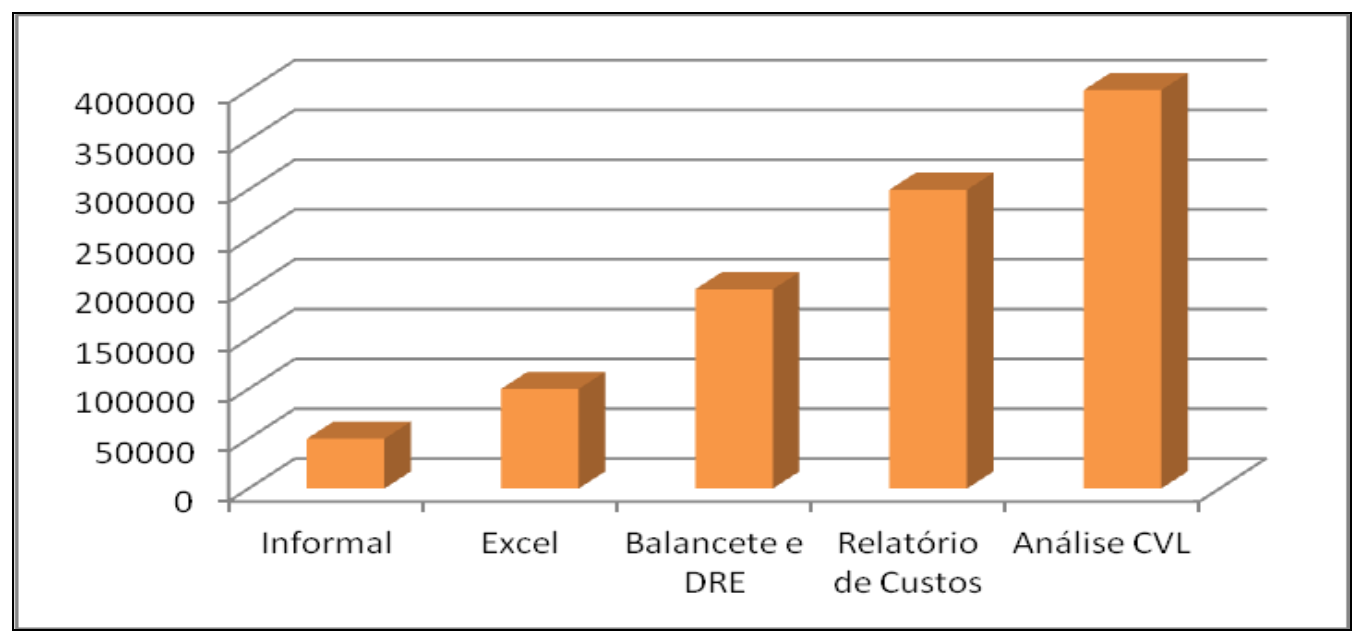

Gráfico 1 - Associação entre nível de faturamento (proxy para tamanho) e utilização de ferramentas gerenciais.

Fonte: Dados da Pesquisa (2013). 
O Processo Decisório em Propriedades Rurais: análise do uso das ferramentas de gestão pelos produtores de leite do Triângulo Mineiro

Paulo Henrique Fonseca de Melo, Jacqueline Veneroso Alves da Cunha, Norton Cruz Freitas Bahia

Nesse contexto, ressalta-se que o volume de operações realizadas em uma entidade se relaciona paralelamente à necessidade de adoção de mecanismos informativos para planejamento, execução, controle e adoção de medidas corretivas, em prol de uma melhor alocação dos recursos disponíveis. No mundo globalizado e competitivo em que as empresas estão inseridas, onde os recursos são cada dia mais escassos, a adoção de ferramentas gerenciais, notadamente advindas da contabilidade, principal responsável por servir de meio de comunicação entre empresa e mercado, além de fornecer mecanismos para administração/orientação, torna-se imprescindível. Ou seja, quanto maior a estrutura organizacional de uma empresa, maior a necessidade de se organizar, conforme observado no Gráfico 1.

Além disso, oito dos 15 médios produtores rurais (53,3\% dos entrevistados) possuem assessoria contábil, sendo que, 5 deles utiliza apenas balancetes e demonstrações de resultado como ferramentas para auxiliar a administração do negócio. Os entrevistados evidenciam que só utilizam esses instrumentos por se tratar dos únicos disponibilizados pela assessoria contábil.

Esse fato ilustra a efetiva necessidade dos profissionais contábeis elucidarem os benefícios de ferramentas gerenciais como os relatórios de custos e análises provenientes da relação custo-volume-lucro (CVL). Cabe salientar ainda que a preparação do profissional contábil é imprescindível tanto para a disseminação dos benefícios proporcionados pela contabilidade e suas ferramentas gerenciais, quanto para a correta aplicação dos procedimentos, normas e práticas contábeis. $O$ desconhecimento da contabilidade por parte dos pequenos e médios produtores rurais está relacionado com a falta de preparação do profissional contábil, o que, inclusive, se caracteriza como um dos desafios do processo de convergência contábil internacional, evento importantíssimo que tem sido destaque no ambiente contábil nos últimos anos.

Bastos (2011) corrobora e ressalta a fragilidade da contabilidade rural como instrumento de gestão. Os resultados evidenciam que, em geral, a contabilidade rural é uma lacuna na formação dos profissionais contábeis pesquisados no estado do Ceará e que seus conhecimentos sobre o tema são bastante limitados. Sendo assim, percebe- 
se que são enormes as limitações da contabilidade rural como instrumento de apoio e gestão das propriedades rurais, sendo, imprescindível, a difusão de seus conceitos e procedimentos, tanto a usuários quanto aos produtores da informação contábil.

A partir dos dados citados, percebe-se também que $38,1 \%$ dos entrevistados possuem contabilidade somente para cumprir demandas fiscais e trabalhistas. A contabilidade no setor rural pode, além de outras coisas, orientar as operações, medir o desempenho e apoiar o planejamento das atividades, buscando, juntamente com outros profissionais, decidir o quê, quanto e como produzir. A contabilidade rural, assim, pode apoiar os administradores rurais no processo decisório, subsidiando-os com informações precisas e tempestivas, de forma que estes possam tomar as decisões mais acertadas.

Ulrich (2009) ressalta que o gestor do agronegócio deve estar sempre em afinidade estreita com a contabilidade, pois esta serve não apenas para Ihe informar sobre créditos ou débitos, serve para lhe mostrar quais os possíveis caminhos a serem trilhados, evitando riscos desnecessários, visando a lucratividade, crescimento e eficácia na gestão.

No Gráfico 2, verifica-se que a análise CVL só é utilizada por um dos produtores entrevistados, sendo este o maior deles, já que nesse contexto o faturamento é utilizado como proxy de tamanho.

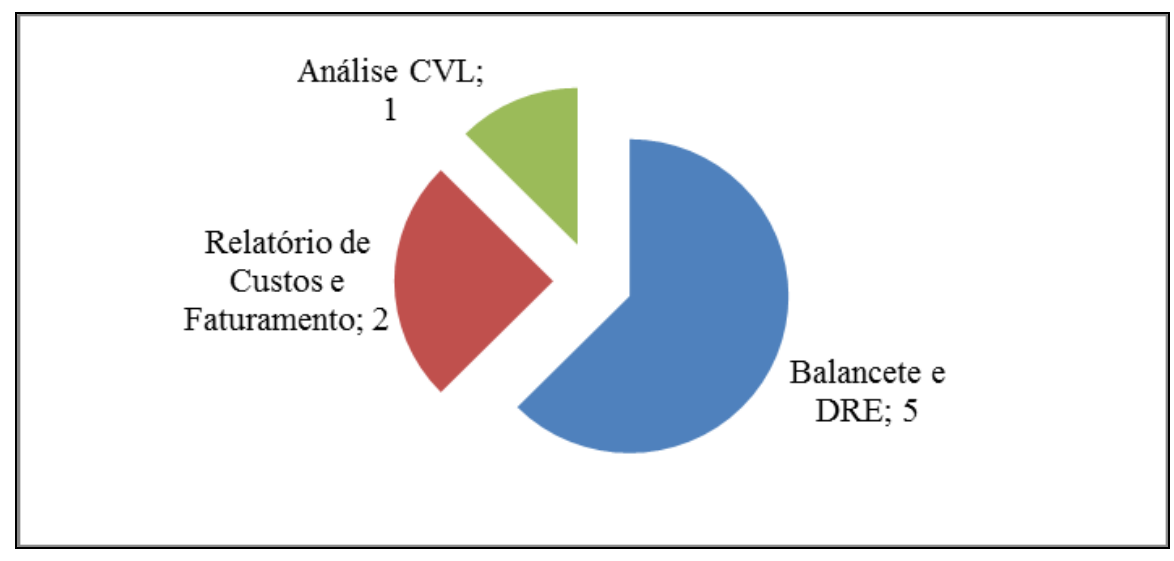

Gráfico 2 - Ferramentas utilizadas por quem possui assessoria contábil. Fonte: Dados da Pesquisa (2013). 
O Processo Decisório em Propriedades Rurais: análise do uso das ferramentas de gestão pelos produtores de leite do Triângulo Mineiro

Paulo Henrique Fonseca de Melo, Jacqueline Veneroso Alves da Cunha, Norton Cruz Freitas Bahia

Quanto aos critérios destacados pelos produtores rurais para detectar redução de lucros, aumento de custos e despesas, objetivando a maximização dos resultados, o levantamento possibilitou constatar que são levados em conta fatores como a rentabilidade e a preservação do solo, sendo a experiência grande impulsionador e mecanismo sinalizador para qualquer decisão tomada pelos pequenos produtores rurais que desconhecem os benefícios da contabilidade. Cabe destacar que há interesse dos produtores rurais pela adoção de assessoria contábil, já que conhecem as dificuldades do setor de atuação, que é permeado por incertezas, ameaças e oportunidades, e entendem que a contabilidade pode ter grande utilidade para redução de custos e aumento da produtividade do empreendimento.

Entretanto, ressaltam que a relação custo-benefício das assessorias contábeis é a grande vilã, responsável pela não incorporação da contabilidade nos pequenos empreendimentos rurais. Cabe ressaltar ainda que quando questionados sobre uma possível assessoria com parceria de uma cooperativa ou órgão representativo, os produtores se mostraram favoráveis. Os produtores destacaram os altos custos de produção no agronegócio, e enfatizaram a possibilidade de redução desses custos com o auxílio de ferramentas gerenciais provenientes da contabilidade. Contudo, salientam que, sem parcerias ou cooperativismo, a assessoria contábil aumentaria ainda mais os custos do agronegócio.

Corroborando, Kruger et al. (2014) identificaram a carência na utilização da contabilidade como instrumento de apoio e controle para a gestão das propriedades rurais. Elevados níveis de desconhecimento e falta de controle de procedimentos de gestão proporcionados pela contabilidade foram verificados neste estudo.

Quanto à captação de financiamentos e aplicação de recursos, percebeu-se uma forte ligação entre financiamentos realizados e assessoria contábil. Como pode ser percebido no Gráfico 3, os financiamentos são realizados por produtores que possuem pelo menos contabilidade para fins fiscais, sendo $80 \%$ dos financiamentos realizados por grandes produtores rurais, que de certa forma utilizam a contabilidade e algumas ferramentas gerenciais, como relatórios de custos e faturamento, além da análise CVL. 
O Processo Decisório em Propriedades Rurais: análise do uso das ferramentas de gestão pelos produtores de leite do Triângulo Mineiro

Paulo Henrique Fonseca de Melo, Jacqueline Veneroso Alves da Cunha, Norton Cruz Freitas Bahia

Importa destacar, nesse contexto, que os financiamentos são realizados objetivando maiores resultados, sendo aplicados em animais, aquisição de máquinas e equipamentos e beneficiamento do solo. A contabilidade nesse âmbito torna-se importante tanto para fins de atendimento das exigências das instituições financeiras quanto para fins de correta aplicação dos recursos.

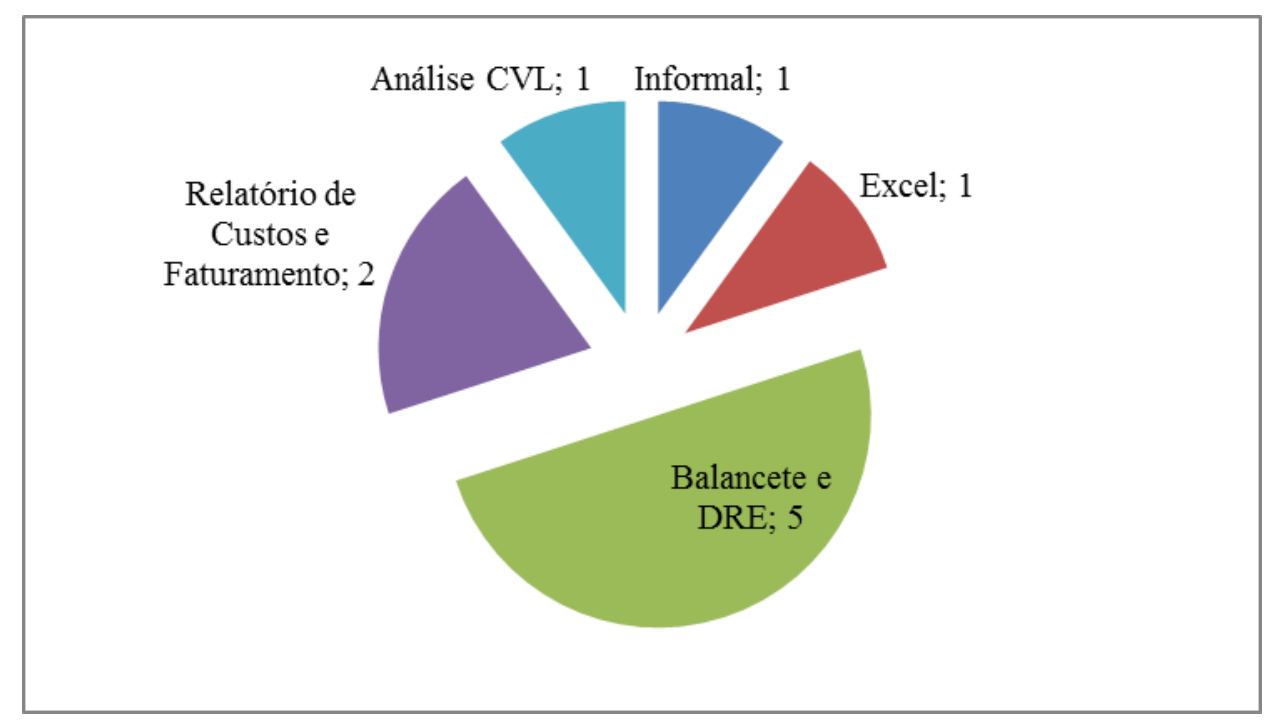

Gráfico 3 - Associação entre financiamentos realizados e ferramentas gerenciais utilizadas pelos produtores.

Fonte: Dados da Pesquisa (2013).

Procurou-se identificar, também, se os pequenos e médios produtores rurais realizam algum planejamento das atividades, com o objetivo de atingir alguma meta considerando critérios para o aumento da produção, para o aumento da produtividade ou para redução de custos e despesas. Em resposta ao questionamento, 42,9\% dos entrevistados declaram que possuem algum tipo de planejamento das atividades operacionais, com o auxílio de terceiros, e não planejamento financeiro.

A contabilidade rural se caracteriza como um dos principais sistemas de controle e informação dos empreendimentos rurais. A partir da análise de ferramentas de gestão proporcionadas pela contabilidade, é possível verificar a situação da empresa, sob os mais diversos enfoques, como análise estrutural, de evolução, de solvência e garantia, de fontes de financiamento, de retorno e de investimentos. A tarefa de gerar 
O Processo Decisório em Propriedades Rurais: análise do uso das ferramentas de gestão pelos produtores de leite do Triângulo Mineiro

Paulo Henrique Fonseca de Melo, Jacqueline Veneroso Alves da Cunha, Norton Cruz Freitas Bahia

informações gerenciais que venham a subsidiar as decisões, com base em dados fidedignos, consistentes e reais, é uma dificuldade permanente para os produtores rurais, sendo papel da contabilidade rural gerar tais informações.

A recessão econômica no Brasil impõe aos empresários rurais excelência na administração dos recursos, antes, dentro e depois da porteira. Na fazenda, o produtor rural tem que dar espaço ao empresário rural, cada dia mais buscando conhecimento, atento aos riscos e entendendo o funcionamento dos mecanismos que possam fazer a empresa crescer com sustentabilidade. O planejamento e monitoramento dos riscos e a compreensão das ameaças e oportunidades proporcionadas pelo ambiente, assim como dos pontos fortes e fracos, possibilitarão que o produtor venha a crescer com segurança.

A distância entre produtor e contador deve ser reduzida no cenário de crescimento e fortalecimento do segmento agropecuário, pois a presença efetiva deste último é fundamental para identificar, mensurar e atender às necessidades do setor, indicando as melhores decisões e contribuindo para o melhor gerenciamento das oportunidades e, consequentemente, aumento da rentabilidade. O contador será cada dia mais importante nesse segmento da economia, à medida que este for crescendo e se tornando mais complexo.

\section{CONSIDERAÇÕES FINAIS}

Este estudo teve por objetivo identificar as ferramentas de gestão que os pequenos e médios produtores rurais vêm utilizando para subsidiar suas decisões. Adicionalmente, pretendeu-se identificar em que nível essas ferramentas vêm sendo utilizadas. O estudo se baseou na Teoria de Crescimento da Firma, que procura compreender o processo de crescimento da firma e as limitações internas e externas à sua expansão. Portanto, identifica os limites de crescimento da firma a partir da capacidade do empresário de identificar oportunidades produtivas que possam ser exploradas. 
O Processo Decisório em Propriedades Rurais: análise do uso das ferramentas de gestão pelos produtores de leite do Triângulo Mineiro

Paulo Henrique Fonseca de Melo, Jacqueline Veneroso Alves da Cunha, Norton Cruz Freitas Bahia

Procurou-se verificar também os pontos fortes e os pontos fracos, além de fontes alternativas utilizadas pelos entrevistados. Todos esses fatores devem ser estudados por acadêmicos e preparadores, já que estão estritamente relacionados à múltipla finalidade da contabilidade de servir como meio de comunicação entre empresa e mercado, propiciar capacidade informacional e ser uma ferramenta de administração/orientação, fornecendo mecanismos sinalizadores para melhorar a gestão dos recursos disponíveis.

A população constituiu-se dos produtores de leite da Coopatos, sendo que a amostra foi definida por relevância e acessibilidade, reunindo 42 produtores de leite da cooperativa. $O$ instrumento de coleta de dados da pesquisa foi apoiado por perguntas abertas e fechadas nas entrevistas semiestruturadas e por algumas técnicas quantitativas utilizadas na análise dos resultados.

Pela análise dos dados, constatou-se que a contabilidade é um importante instrumento para os empreendimentos rurais, ou seja, o agronegócio, pois gera informações que possibilitam analisar a situação empresarial, pelos mais diversos ângulos, como: análises estruturais, de evolução, solvência, fontes de financiamento, retorno e de investimentos. Tais informações são imprescindíveis para o processo decisório como um todo, como na percepção dos médios produtores rurais, que enfatizaram a importância das informações contábil-financeiras, tendo em vista a elevação do nível de qualidade das decisões.

Verificou-se também que os maiores empreendimentos rurais já conhecem as ferramentas contábeis, como balanços, balancetes, demonstrações de resultado e outros relatórios de faturamento, custos de produção e análise CVL. Percebe-se que na medida em que aumenta a demanda por decisões nos empreendimentos rurais, a contabilidade vai ganhando mais espaço. Nesse âmbito, cabe ressaltar que a grande maioria dos empreendimentos, mesmo as grandes propriedades rurais, usufruem muito pouco dos benefícios proporcionados pelas ferramentas gerenciais, já que a grande maioria deles só utiliza balancetes e demonstrações de resultado como relatórios contábeis, por se tratar dos únicos disponibilizados pela assessoria contábil. 
O Processo Decisório em Propriedades Rurais: análise do uso das ferramentas de gestão pelos produtores de leite do Triângulo Mineiro

Paulo Henrique Fonseca de Melo, Jacqueline Veneroso Alves da Cunha, Norton Cruz Freitas Bahia

Entretanto, os pequenos produtores estão inseridos na informalidade, utilizando como ferramentas para planejamento e controle apenas anotações e planilhas eletrônicas elaboradas com base em suas próprias experiências, e, às vezes, único instrumento de auxílio ao processo decisório. Esse fato sugere que soluções precisam ser investigadas objetivando o acesso às ferramentas contábil-financeiras por parte dos pequenos produtores rurais, que têm interesse em adotar as ferramentas gerenciais e usufruir dos benefícios que elas podem proporcionar. Cabe destacar que, apesar das conclusões limitarem-se á amostra pesquisada, observa-se que os resultados corroboram com outras pesquisas realizadas em diferentes regiões como os trabalhos de Kruger et al. (2014), Ulrich (2009) e Bastos (2011).

Nesse sentido, importa ressaltar que a contabilidade rural ainda não é muito utilizada, principalmente entre os pequenos produtores, que a utilizam somente para fins fiscais. Na conscientização do pequeno produtor, aquele que produz para subsistência e vendas em pequena escala, para o que a legislação não exige escrituração regular, deve ressaltar o fato de que o planejamento, execução e controle da produção, pilares da administração que, subsidiados por ferramentas contábilfinanceiras, são necessários em quaisquer empreendimentos, independentemente de seu porte e setor, caracterizando-se como uma complexa tarefa ligada ao profissional contábil.

No que tange à aplicação da Teoria de Crescimento da Firma considera-se que a decisão de expandir as atividades é uma constante no processo decisório das empresas, independentemente das condições externas e, nesse sentido, a obtenção de ferramentas de controle por parte dos gestores, que lhes possibilitem identificar e analisar, além de seus pontos fortes e pontos fracos, as ameaças e oportunidades no ambiente em que estão inseridos, em prol da obtenção de vantagem competitiva, melhores resultados e consequente crescimento. Nesse contexto, percebe-se a estreita relação entre informações contábil-financeiras com utilização de ferramentas gerenciais e a Teoria de Crescimento da Firma. 
O Processo Decisório em Propriedades Rurais: análise do uso das ferramentas de gestão pelos produtores de leite do Triângulo Mineiro

Paulo Henrique Fonseca de Melo, Jacqueline Veneroso Alves da Cunha, Norton Cruz Freitas Bahia

O crescimento econômico do Brasil e do mundo está diretamente ligado ao desenvolvimento de seus vários setores, dentre eles o agronegócio. Logo, o crescimento desse setor coloca o contador como figura estratégica e de destaque nesse contexto, desempenhando papel relevante, ao auxiliar o produtor rural na implementação de práticas eficazes de gerenciamento, objetivando a continuidade e crescimento do projeto. É necessário que os produtores rurais sejam conscientizados da importância das ferramentas contábil-financeiras na gestão de suas atividades, principalmente por se tratar de ações que envolvem altos custos de produção, sazonalidades, intempéries, flutuações de preços e outras variáveis que precisam ser controladas em prol da rentabilidade do negócio.

Enfim, o setor agropecuário, contando com assessoria técnica e contábil, além de apoio das classes representativas e incentivos provenientes do Governo Federal, poderá se destacar cada dia mais na economia brasileira e mundial. Assim, pode-se concluir que essa temática está estritamente relacionada com a finalidade principal da informação contábil, que é ser relevante (capacidade preditiva e de feedback) e representar com fidedignidade aquilo a que se propõe (neutra, livre de erros e de vieses), sendo útil como subsídio para as decisões dos stakeholders. Isso, além de servir para que a contabilidade possa exercer sua dupla finalidade de informação e administração/orientação, fornecendo mecanismos de sinalização, orientação e controle em prol da adequada gestão dos recursos colocados à disposição do gestor e congruência entre os objetivos dos stakeholders. Essa preocupação surge concomitantemente a eventos e investigações que procuram elucidar a utilidade e relevância da informação contábil. Nos mercados reais, imperfeitos, fontes informacionais concorrentes surgem a todo momento, cabendo à contabilidade ser flexível, mutável e procurar evoluir, já que está inserida em um complexo ambiente econômico, mantendo o seu grande valor como plataforma informacional para a economia.

Para futuras pesquisas, sugere-se a análise da utilidade e relevância das ferramentas gerenciais e relatórios contábil-financeiros em termos essencialmente 
O Processo Decisório em Propriedades Rurais: análise do uso das ferramentas de gestão pelos produtores de leite do Triângulo Mineiro

Paulo Henrique Fonseca de Melo, Jacqueline Veneroso Alves da Cunha, Norton Cruz Freitas Bahia

qualitativos. Investigando-se somente empreendimentos rurais que contam com assessoria contábil e utilizam ferramentas gerenciais contábil-financeiras, será possível compreender os benefícios proporcionados pela contabilidade para os produtores rurais. Pesquisas empíricas poderiam investigar se o processo contábil tem gerado informação de qualidade. Análises qualitativas, e não só quantitativas, têm grande relevância para o progresso da contabilidade. Cabe ressaltar ainda que, com investigações acerca dessa temática, será possível elucidar os benefícios da adoção da contabilidade. Enfim, soluções junto a cooperativas rurais e órgãos representativos também devem ser pesquisadas, em prol do agronegócio e, mais especificamente, do produtor rural, para a difusão da contabilidade nesse meio.

\section{REFERÊNCIAS}

ALMEIDA, M. S. et al. (2012). Investigação empírica do crescimento das empresas da Bovespa: análise de variáveis financeiras e comparação de diferentes tipologias de crescimento. In: SEMINÁRIOS EM ADMINISTRAÇÃO - SEMEAD, 15, 2012, São Paulo. Anais...São Paulo: FEA/USP.

ATSBEHA, D.M. et al. (2012). Animal breeding and productivity growth of dairy farms. IDEAS - Division of the Federal Reserve Bank of St. Louis. American Journal of Agricultural Economics, v. 94, n. 4, p. 996-1012.

AVELAR, E .A. et al. (2011). Analise da relação entre diversificação e risco: estudo empírico em empresas de capital aberto brasileiras entre os anos de 2000 e 2007. In: SEMINÁRIOS EM ADMINISTRAÇÃO - SEMEAD, 14., São Paulo, 2011. Anais...São Paulo: FEA/USP.

AZEVEDO, P. F.; BANKUTI, F. I. (2001). Na clandestinidade: o mercado informal de carne bovina. In: INTERNATIONAL CONFERENCE ON AGRI-FOOD CHAIN/NETWORKS ECONOMICS AND MANAGEMENT, 3, 2001, Ribeirão Preto. Anais...Ribeirão Preto: IEA.

BANKUTI, F. I.; SOUZA FILHO, H. M. (2006). A informalidade em sistemas agroindustriais: os casos dos sistemas agroindustriais de carne bovina e do leite. In: ZUIN, L. F. S. e QUEIRÒZ, T. R. Agronegócios: gestão e inovação. São Paulo: Saraiva, p. 57-90. 
O Processo Decisório em Propriedades Rurais: análise do uso das ferramentas de gestão pelos produtores de leite do Triângulo Mineiro

Paulo Henrique Fonseca de Melo, Jacqueline Veneroso Alves da Cunha, Norton Cruz Freitas Bahia

BASTOS, R. R. (2011). Contabilidade do Agronegócio: um estudo exploratório sobre os conhecimentos dos contabilistas do município de Quixadá na região do sertão central do estado do Ceará. Revista Razão Contábil \& Finanças, Fortaleza, v. 2, n. 2, 2011.

BEUREN, I. M. (2000). Gerenciamento da informação: um recurso estratégico no processo de gestão empresarial. 2. ed. São Paulo: Atlas, 104p.

DALMOLIN, A.; SILVÉRIO, A. C. (2011). Os benefícios da contabilidade rural para uma empresa agrícola de pequeno porte: um estudo caso. Revista e-ESTUDANTE Electronic Accounting and Management, v. 3, n. 3.

DAVENPORT, T. H. (2000). Ecologia da informação: por que só a tecnologia não basta para o sucesso na era da informação. São Paulo: Futura, 316p.

GOLDRATT, E. M. (1991). Garimpando informação num oceano de dados: a síndrome do palheiro. São Paulo: C. Fullmann, 243p.

GOMES, A. (2006). Identificação dos aspectos contábeis constantes nas pesquisas agropecuárias para a expansão das exportações de produtos agrícolas brasileiros no âmbito do estado de Minas Gerais. In: CONGRESSO USP DE INICIAÇÃO CIENTIFICA EM CONTABILIDADE, 3., 2006, São Paulo. Anais...São Paulo: USP.

HOFER, E. et al. (2006). Contabilidade como ferramenta gerencial para a atividade rural: um estudo de caso. In: ENCONTRO DA ASSOCIAÇÃO NACIONAL DE PÓSGRADUAÇÃO E PESQUISA EM ADMINISTRAÇÃO, 30., 2006, Salvador. Anais... Salvador: ANPAD.

HOFER, E. et al. (2010). A relevância do controle contábil para o desenvolvimento do agronegócio em pequenas e médias propriedades rurais. In: CONGRESSO DA SOCIEDADE BRASILEIRA DE ECONOMIA, ADMINISTRAÇÃO E SOCIOLOGIA RURAL, 48, 2010, Campo Grande. Anais...Campo Grande: SOBER.

IBGE - Instituto Brasileiro de Geografia e Estatística. (2013). Estatística da produção pecuária. Disponível em: <http://www.ibge.gov.br/home/estatistica/indicadores/agropecuaria/producaoagropecuar ia/abate-leite-couro-ovos_201301_publ_completa.pdf>. Acesso em 10 jun. 2013.

IRWIN, E. G. et al. (2010). Acentury of research on rural development and regional issues. Oxford Journals Economics \& Social Sciences American Journal of Agricultural Economics, v. 92, n. 2, p. 522-553. 
O Processo Decisório em Propriedades Rurais: análise do uso das ferramentas de gestão pelos produtores de leite do Triângulo Mineiro

Paulo Henrique Fonseca de Melo, Jacqueline Veneroso Alves da Cunha, Norton Cruz Freitas Bahia

KHENE, C. P. et al. (2011). Sustainable rural ICT project management practice for developing countries: investigating the Dwesa and Rumep projects. Information Technology for Development, v. 17, n. 3, p. 187-212.

KING, R. P. et al. (2010). Agribusiness economics and management. Oxford Journals Economics \& Social Sciences American Journal of Agricultural Economics, v. 92, n. 2, p. 554-570.

KRUGER, et al. (2014). A contabilidade como instrumento de gestão dos estabelecimentos rurais. REUNIR: Revista de Administração, Contabilidade e Sustentabilidade, v. 2, n. 4, p. 134-153.

McGEE, J.; PRUSAK, L. (1994). Gerenciamento estratégico da informação: aumente a competitividade e a eficiência de sua empresa utilizando a informação. Rio de Janeiro: Campus.

MILKPOINT. Relatório completo do Top 100 MilkPoint - e-book. Disponível em: <http://www.milkpoint.com.br/top100-milkpoint-2013-Ip/>. Acesso em: 01/jun/2013.

PENROSE, E. (2006). Teoria do crescimento da firma. São Paulo: Ed. Unicamp.

SANTOS, K. D. et al. (2007). Alianças estratégicas no cooperativismo de leite: um estudo de caso. In: CONGRESSO DA SOCIEDADE BRASILEIRA DE ECONOMIA, ADMINISTRAÇÃO E SOCIOLOGIA RURAL, 45., 2007, Londrina. Anais...Brasília: SOBER

SEBRAE - Serviço Brasileiro de Apoio às Micro e Pequenas Empresas. (2013). Quero melhorar minha empresa. Disponível em: <http://www.sebrae.com.br/momento/queromelhorar-minha-empresa/comece-por-voce/empreendedorismo>. Acesso em: 30/mai/ 2013.

SELL, G. K. (2004). Uma sistemática para inserir a contabilidade gerencial no processo decisório nas pequenas e medias empresas: um estudo de caso. 2004. $109 \mathrm{f}$. (Dissertação de Mestrado). Universidade Federal de Santa Catarina - UFSC, Florianópolis, SC.

STROEHER, Â. M.; FREITAS, H. (2008). O uso das informações contábeis na tomada de decisão em pequenas empresas. Revista de Administração-eletrônica, São Paulo, v.1, n.1, jan./jun.

ULRICH, E. R. (2009). Contabilidade rural e perspectivas da gestão no agronegócio. Revista de Administração e Ciências Contábeis do IDEAU, v. 9, n. 4. 
O Processo Decisório em Propriedades Rurais: análise do uso das ferramentas de gestão pelos produtores de leite do Triângulo Mineiro

Paulo Henrique Fonseca de Melo, Jacqueline Veneroso Alves da Cunha, Norton Cruz Freitas Bahia

VALENTIM, M. L. P. (2003). O processo de inteligência competitiva em organizações. Revista de Ciência da Informação, v. 4, n. 3, jun

Data de Submissão: 24/02/2015

Data de Aceite: 15/03/2016 